\title{
El carlismo aragonés en armas. La revuelta de 1855
}

\author{
Antonio CARIDAD SALVAdOR \\ IES Peset Aleixandre (Paterna, Valencia) \\ antonio_caridad@ya.com
}

Recibido: $25 / 06 / 2013$

Aceptado: 26/05/2014

\section{RESUMEN}

En 1855, aprovechando la llegada al poder de los progresistas, los carlistas organizaron una revuelta, a la que esperaban atraerse a los sectores más conservadores del moderantismo. Pero esto no sólo no se produjo, sino que el respaldo popular de la rebelión fue mucho menor del esperado. Además, en Aragón la conjura fue descubierta por las autoridades, lo que precipitó su inicio y facilitó su rápido final. Al final, tras 19 días de correrías y de persecuciones, los carlistas aragoneses fueron totalmente derrotados. El fracaso de la revuelta mostró que el carlismo había perdido el apoyo de gran parte de la población aragonesa, en parte por la mejora de la economía, pero también por el mal recuerdo que tenían de la última guerra y por la preferencia de los sectores conservadores por el liberalismo moderado.

Palabras clave: Carlismo, liberalismo, historia militar, historia de Aragón, Bienio Progresista

\section{The Aragonese Carlism in Arms. The 1855 Revolt}

\begin{abstract}
In 1855, taking advantage of the reforms of the progressive government, the carlists organized a revolt in which they expected to attract the most conservative sectors of the Moderantism. But this didn't happen and the popular support was much lesser than expected. Besides that, in Aragon the plot was discovered by the authorities, which accelerated its beginning and made its failure easier. In the end, after 19 days of marches and pursuits, the Aragonese carlists were totally defeated. The failure of the revolt showed that the Carlism had lost the support of much of the Aragonese population, in part because the improvement of the economy, but also because the bad memory they had of the last war and the preference of the conservative for moderate Liberalism.
\end{abstract}

Key words: Carlism, liberalism, military history, history of Aragon, Progressive Biennium

Referencia normalizada: Caridad Salvador, A. (2014). "El carlismo aragonés en armas. Las revuleta de 1855". Cuadernos de Historia Contemporánea, Vol. 36, páginas 165-188.

Sumario: 1.Introducción. 2. Preparativos. 3. La insurrección. 4. Conclusiones. 5. Bibliografía. 


\section{Introducción}

Aragón es una de las regiones de España en las que más fuerza tuvo la reacción antiliberal, primero bajo la bandera del realismo y más tarde en las sucesivas guerras carlistas. De hecho, la primera revuelta carlista de España se produjo precisamente en Aragón, a las órdenes de Capapé, en $1824^{1}$. No tan conocida es la de 1855, que, aunque acabó rápidamente, nos ayuda mucho a entender la evolución del carlismo durante el siglo XIX. Esto es así porque este movimiento no se limita a los dos grandes conflictos de la centuria, sino que incluye numerosas pequeñas rebeliones que nos permiten comprender por qué permanecía poco activo durante largos periodos, para reaparecer con fuerza al cabo de un tiempo.

Sin embargo, estas pequeñas revueltas han recibido muy poca atención por parte de la historiografía. De hecho, en su libro sobre la historia del carlismo Jordi Canal sólo dedicó dos páginas a este levantamiento (en toda España), que apenas se preocupó por interpretar. Tal vez porque no tenía mucho en que basarse, ya que en el mismo trabajo afirmó que no existía ningún estudio sobre los alzamientos carlistas del Bienio Progresista ${ }^{2}$. Desde entonces las cosas han cambiado poco, pues en 2007 Mari Cruz Rubio y María Talavera publicaron una amplísima recopilación de la bibliografía sobre el carlismo, en la que no encontramos casi nada sobre la revuelta de 1855. Lo único que aparece mencionado es un breve artículo de dos páginas escrito por Ferran Sánchez Agustí y que se limita a la entrada de los carlistas en un pueblo catalán ${ }^{3}$. Cuatro años después Jordi Canal afirmaba que las décadas de 1840 y 1850 están entre las etapas menos estudiadas de la historia del carlismo ${ }^{4}$.

Esta falta de estudios sobre la rebelión de 1855 me ha obligado a basar mi estudio en las fuentes de la época, pues no hay casi nada reciente sobre lo que apoyarse. Para ello he utilizado sobre todo la prensa valenciana y aragonesa, así como los documentos que he encontrado al respecto en el archivo de la Diputación de Zaragoza. Todo ello lo he complementado con las obras clásicas de Antonio Pirala, Pablo de Córdoba y Melchor Ferrer, en las que se hace una referencia a dicha rebelión. Con estas fuentes, y con una reflexión personal apoyada en parte en mis conocimientos sobre la Primera Guerra Carlista ${ }^{5}$, he tratado de explicar un alzamiento que, aunque duró

\footnotetext{
1 *Siglas utilizadas en este artículo: DMV (Diario Mercantil de Valencia), LL (La Libertad), BOPZ (Boletín Oficial de la Provincia de Zaragoza), AMC (Archivo Municipal de Castellfort), ADPZ (Archivo de la Diputación Provincial de Zaragoza), AGMS (Archivo General Militar de Segovia), AGA (Archivo General de la Administración), ADPO (Archivos Departamentales de los Pirineos Orientales) y ADA (Archivos Departamentales de Ain).

PIRALA, Antonio: Historia de la guerra civil y de los partidos liberal y carlista, Madrid, Turner / Historia 16,1984, v, 1, p. 42.

2 CANAL, Jordi: El carlismo. Dos siglos de contrarrevolución en España, Madrid, Alianza editorial, 2000, pp. 139, 140 y 466.

3 RUBIO, Mari Cruz y TALAVERA, María: El carlismo, Madrid, Consejo Nacional de Investigaciones Científicas, 2007. SÁNCHEZ I AGUSTÍ, Ferran, "Entrada dels carlins a Balsareny l'any 1855" en Bulletí del Cercle Cultural de Balsareny, $\mathrm{n}^{\circ}$ 184, 1991, pp. 7 y 8.

4 CANAL, Jordi: "El carlisme: notes històriques i historiogràfiques" en Lluc: revista de cultura i d'idees, $\mathrm{n}^{\circ} 877,2011$, p. 17.

5 Véase mi tesis doctoral. CARIDAD, Antonio: El carlismo en el País Valenciano y Teruel (1833-1840), Valencia, Universidad de Valencia, 2010.
} 
poco y acabó fracasando, nos dice mucho sobre las motivaciones de los carlistas y nos ayuda a entender, tanto su fracaso en estos años, como su facilidad para perdurar durante tanto tiempo.

\section{Preparativos}

Empezaré mi relato en 1850, cuando los absolutistas aragoneses se estaban recuperando de su derrota en la revuelta de los matiners. Este conflicto, aunque se centró en Cataluña, también afectó a Aragón, donde operaron durante varios meses las partidas de Gamundi, Montañés, Aznar y Griñón. Sin embargo, en esta ocasión (y al contrario de lo que había sucedido durante la guerra de los siete años) el apoyo popular fue escaso y esto hizo que las gavillas rebeldes fueran pequeñas y no pudieran mantenerse durante mucho tiempo.

Pero el fracaso no desmoralizó a los carlistas, que siguieron con sus tentativas armadas, creyendo que contaban con el respaldo de la mayor parte de la población. Esto les llevó a intentar numerosas rebeliones, que tenían muy pocas posibilidades de éxito y que fueron fácilmente desarticuladas por las autoridades. Una de ellas fue la que se produjo en Alcañiz en agosto de 1850 y que no debió de pasar de una mera conspiración. En esta ocasión los carlistas tenían previsto desembarcar armas y voluntarios por los Alfaques (Tarragona), pero esto no pudo llevarse a cabo, gracias a las disposiciones del capitán general de Valencia, el general Juan Villalonga ${ }^{6}$.

Tras dos años de calma, en agosto de 1852 apareció una partida de carlistas armados por los términos de Manzanera, San Agustín y Alcotas, todos ellos en el sur de la provincia de Teruel. Dicha fuerza empezó con siete hombres, pero creció en poco tiempo, llegando a contar con 20 guerrilleros, que a su paso por Alcotas dieron vivas a Cabrera. Rápidamente las autoridades enviaron en su persecución a varias partidas del ejército y de la guardia civil, así como a los somatenes de los pueblos. Los rebeldes, que en vez de saquear pagaban cuanto tomaban, se dividieron en pequeños grupos y se ocultaron, sin que se produjera ningún combate con las tropas de la reina. Poco después se dejó de hablar de ellos y el "alzamiento" se desvaneció, probablemente por falta de dinero o de apoyo entre la población civil ${ }^{7}$.

Un año más tarde el conde de Montemolín (pretendiente carlista al trono), viendo el fracaso de estos alzamientos improvisados, desautorizó toda rebelión que se hiciera sin su conocimiento. Pero esto no impidió que algunos "latro-facciosos" aparecieran poco después en los confines de Aragón y Cataluña, lo que obligó a salir de Zaragoza a cuatro compañías del regimiento de granaderos, el 4 de mayo de 1853. Ese mismo mes 22 hombres armados (seis de ellos a caballo) fueron vistos cruzando la carretera de Teruel a Valencia, entre Sarrión y La Puebla de Valverde. No molestaron a nadie ni se les oyó una palabra, pero es probable que pertenecieran al bando carlista y que esperasen algún acontecimiento para promover de nuevo la guerra civil ${ }^{8}$. No obstan-

\footnotetext{
${ }^{6} D M V, 30$ de agosto de 1850 .

$7 D M V, 6$ de septiembre de 1852 .

$8 D M V, 25$ de marzo, 10 de mayo y 22 de noviembre de 1853.
} 
te, al final todo esto quedó en nada, puesto que las bandas rebeldes se disolvieron enseguida, sin producirse combate alguno.

En verano del año siguiente se produjo una revolución que llevó al poder a los progresistas, lo que indujo a los carlistas a realizar nuevos intentos. Probablemente pensaran que muchos absolutistas moderados se pondrían de su parte ahora, al ver en el poder a sus peores enemigos. De esta manera, el 27 de julio de 1854 el comandante militar de Castellote comunicó que en Las Parras habían aparecido los Marco, famosos cabecillas de la facción ${ }^{9}$. Los tres hermanos pertenecían a una familia de hacendados del Jiloca y el mayor de ellos, Manuel, había combatido en la primera guerra carlista, dirigiendo el $6^{\circ}$ batallón de Aragón ${ }^{10}$. Esto, y "la circunstancia de ser el partido de Castellote y los demás contiguos enteramente carlistas" causó cierta alarma, pero al final no sucedió nada. Quizás el rumor fuera falso o tal vez los Marco sólo estuvieran tanteando el terreno, en previsión de futuros alzamientos ${ }^{11}$.

A partir de septiembre los carlistas empezaron a moverse también desde el exilio, yendo de un sitio para otro y celebrando muchas reuniones. Uno de los líderes del complot era Joaquín Elío, que recibió instrucciones del conde de Montemolín para entablar contactos con jefes y oficiales del ejército ${ }^{12}$. Poco después uno de los caudillos carlistas con más prestigio de Aragón, Pascual Gamundi, recorrió de incógnito el Maestrazgo, hablando a sus partidarios y reuniéndose con sus amigos, probablemente con vistas a una nueva rebelión ${ }^{13}$. También por esas fechas un antiguo coronel de Cabrera trató de formar una partida con los presos de la cárcel de Albarracín, pero el intento fue abortado por el comandante general de Teruel ${ }^{14}$.

Al mismo tiempo los carlistas volvieron a utilizar el púlpito como arma de guerra, ya que algunos eclesiásticos aragoneses empezaron a acusar al gobierno de querer acabar con la religión. Para convencer a sus feligreses les decían que iban a ser confiscadas las alhajas más estimadas, que los templos se iban a cerrar y que Dios exigía el sacrificio de sus escogidos, lo que enfervorizó a algunos pueblos, conocidos por sus ideas conservadoras y por su tradición carlista ${ }^{15}$.

Mientras tanto los exiliados continuaban con sus preparativos. El 12 de enero de 1855 tuvo lugar en París una reunión de los principales jefes del carlismo y otros hombres políticos, recientemente convertidos a la causa, para acordar la conducta que el partido monárquico (nombre que ellos se daban) debía tomar, ante la nueva situación en España. A dicho encuentro no asistió el pretendiente, que residía en Nápoles

$9 D M V, 30$ de julio de 1854 .

10 FERRER, Melchor, TEJERA, Domingo y ACEDO, José: Historia del tradicionalismo español, Sevilla, Ediciones Trajano y Editorial Católica Española, 1941-1960, v. 20, pp. 153 y 155. DE JAIME, José María y DE JAIME, José: Manuel Marco y Rodrigo. Marco de Bello, Calamocha, Centro de Estudios del Jiloca, 1992, pp. 25-48.

$11 D M V, 30$ de julio de 1854.

$12 D M V, 30$ de septiembre y 2 de noviembre de 1854.

$13 D M V, 5$ de junio de 1855.

14 PIRALA, Antonio: Historia contemporánea. Segunda parte de la guerra civil. Anales desde 1843 hasta el fallecimiento de don Alfonso XII, Madrid, Felipe González Rojas editor, 1892-1906, v. 1, p. 670.

$15 L L, 11$ de junio de 1855. 
en esa época, pero sí que lo hizo su hermano don Juan, así como Cabrera, Elío y otras personas destacadas ${ }^{16}$.

No sabemos qué se acordó en esa reunión, pero lo más probable es que se decidiera iniciar los preparativos para una sublevación a gran escala, a juzgar por lo que sucedió después. Ya en enero Morella, Estella y otros puntos eran focos de activos trabajos y de maquinaciones de los partidarios de don Carlos. Y unos 2.000 refugiados carlistas, algunos de los cuales trabajaban en el ferrocarril Dax-Bayona, se acercaron a la frontera, mientras Elío, Cabrera y Mon vivían en una agitación permanente, haciendo casi de correos entre la frontera, Londres y París. Para financiar el alzamiento disponían del dinero aportado por Cabrera (casado con una de las mujeres más ricas de Inglaterra) y por los legitimistas franceses, que se sentían muy próximos al carlismo. Además, contaban con la promesa de un empréstito considerable en cuanto consiguieran una plaza fuerte en España. De esta manera, pronto empezó a circular una proclama del conde de Montemolín, mientras que muchos oficiales del ejército eran objeto de lisonjeras ofertas, a fin de atraérselos al bando del pretendiente ${ }^{17}$.

Durante las semanas siguientes continuaron celebrándose reuniones en París, acordándose que Elío se pondría al frente del movimiento en Navarra, mientras que Cabrera lo haría en Cataluña ${ }^{18}$. Al mismo tiempo, los carlistas aragoneses ultimaban su rebelión, que debía estallar entre el 23 y el 27 de mayo. Para ello recibían dinero de Francia, preparaban una proclama y trataban de atraerse al ejército, especialmente a los sargentos ${ }^{19}$. El presidente de la junta legitimista de Zaragoza era Gregorio Puelles, que había nacido en Fuenmayor (La Rioja ${ }^{20}$ y que había sido director de la fábrica de armas que los carlistas tenían en Cantavieja, en $1837^{21}$. Más tarde ascendió a teniente coronel ${ }^{22}$ y se le encargó el mando de la segunda compañía de zapadores, que defendía Morella ${ }^{23}$. Sin embargo, en 1840 cayó la fortaleza y nuestro personaje fue capturado por las tropas de la reina, que lo condujeron al depósito de prisioneros de Zaragoza $^{24}$. Al cabo de un tiempo, fue puesto en libertad y empezó a participar en conspiraciones carlistas en la capital aragonesa ${ }^{25}$. De esta manera, en 1855 Gregorio Puelles se encargaba de preparar una nueva revuelta y recibía toda la correspondencia del conde de Samitier, que a su vez remitía al cura Marcelino Millán, que coordinaba a los conjurados de la zona de Calatayud. También era importante el papel de José Pueyo, pues en su casa se reunían continuamente los implicados en la conjura. Además, este personaje tenía tres sirvientes muy fieles que iban con frecuencia a Caspe,

${ }^{16} D M V, 13$ de enero de 1855.

$17 D M V, 20$ de enero de 1855.

$18 D M V, 3$ de febrero de 1855.

19 PIRALA, Antonio: Historia contemporánea ... v. 1, p. 672. DMV, 5 de junio de 1855.

20 BOPZ, 27 de junio de 1840 .

21 CÓRDOBA, Buenaventura: Vida militar y política de Ramón Cabrera, Madrid, Imprenta de Eusebio Aguado, 1844-1846, v. 2, p. 230.

22 AMC, caja 2, legajos 2-2 y 2-5.

23 CALBO y ROCHINA DE CASTRO, Dámaso: Historia de Cabrera y guerra civil en Aragón, Valencia y Murcia, Madrid, Establecimiento tipográfico de don Vicente Castelló, 1845, p. 530. Calbo afirma que Puelles era comandante.

24 BOPZ, 27 de junio de 1840.

25 ADPZ, vigilancia, caja XVI-1189. 
Alcañiz y otros puntos de Aragón, llevando órdenes de la junta de Zaragoza. Uno de ellos, llamado Eugenio Lalama, había sido teniente en las filas de Cabrera ${ }^{26}$.

En cuanto a los liberales, estaban al tanto de la actividad carlista, aunque ignoraban el detalle de lo que se estaba preparando. De hecho, exageraban la amenaza de sus enemigos, creyendo que estaban ingresando en la milicia nacional y que en algunas provincias controlaban una quinta parte de sus armas. Además, pensaban que los carlistas contaban con apoderarse de tres plazas fuertes (una en Aragón, una en el Maestrazgo y otra en Cataluña) $)^{27}$, algo que sólo resultó ser cierto en el caso de Morella ${ }^{28}$.

Ante esta situación el gobierno tomó cartas en el asunto, apartando del servicio a muchos oficiales de pasado carlista. Otros, sin embargo, no fueron separados, pese a que sus jefes no tenían mucha confianza en ellos $^{29}$. Los temores del gobierno se confirmaron cuando en la tarde del 16 de mayo fueron descubiertos, en una paridera del término de Mediana (a unos $25 \mathrm{~km}$ de Zaragoza), 40 fusiles muy buenos, 80 paquetes de cartuchos y cerca de 100 cananas, que los carlistas habían almacenado allí para utilizar en su insurrección. Entonces se procedió a detener al carretero que condujo allí las armas, al pastor que las custodiaba y al que las había pagado ${ }^{30}$. A esto se añadió que ese mismo día fue avistado, cerca de Puebla de Albortón (a $27 \mathrm{~km}$ de la capital aragonesa) un grupo de 14 hombres armados, que enseguida desaparecieron hacia Muel ${ }^{31}$.

Todo esto llevó a la detención, en la capital aragonesa, de Eugenio Lalama, Pascual Medina y un tal Barber, acusados de reclutar voluntarios para los enemigos de la reina ${ }^{32}$. Al que no se pudo detener fue a Alberto Urries, propietario de la paridera, ya que cuando la policía llegó a su casa ya no estaba, alegando su familia que había salido de cacería ${ }^{33}$. Durante los días siguientes siguieron las diligencias en el juzgado y se estuvo vigilando a los que sospechaba que estaban implicados en el complot. De esta manera, las declaraciones del pastor mencionado llevaron incluso a la detención de los albañiles que habían tapiado el lugar en el que se encontraron las armas ${ }^{34}$. Más importante fue la detención, el 19 de mayo, del comandante carlista José Bello y de un tal Victoriano Giménez, que había formado parte de la policía durante la Década Ominosa. Un día después se prendió a Pascual Aznar (a) el Cojo de Cariñena, destacado caudillo aragonés, que había combatido ya en tres guerras contra los liberales ${ }^{35}$.

Dicho cabecilla había nacido en Cariñena (Zaragoza) en $1800^{36}$ y durante la guerra civil del Trienio combatió en las fuerzas realistas de Capapé, logrando así ascender hasta teniente. En uno de dichos encuentros, que tuvo lugar en Nules en abril de 1823,

\footnotetext{
26 ADPZ, vigilancia, caja XVI-1189.

$27 D M V, 13$ de enero, 3 de febrero y 5 de junio de 1855.

28 PIRALA, Antonio: Historia contemporánea..., v. 1, p. 670.

$29 D M V, 4$ de junio de 1855.

30 LL, 18 de mayo de 1855. ADPZ, vigilancia, caja XVI-1189.

31 ADPZ, vigilancia, caja XVI-1189.

32 FERRER, Melchor, TEJERA, Domingo y ACEDO, José: Historia del tradicionalismo... v. 20, pp. 156 y 157.

33 LL, 18 de mayo de 1855. ADPZ, vigilancia, caja XVI-1189.

$34 L L, 20$ de mayo de 1855.

$35 L L, 21,22$ y 23 de mayo de 1855. ADPZ, gobernación, caja 1210 y vigilancia XVI-1189.

36 AGMS, primera sección, legajo A-2707. $D M V, 7$ de agosto de 1837.
} 
fue gravemente herido en la pierna derecha y desde entonces quedó totalmente impedido de dicha extremidad. Sin embargo, esto no le impidió regresar al ejército, siendo destinado de guarnición a varios puntos. Un año después fue apartado del servicio con licencia ilimitada, lo que debió dejarle en una situación económica difícil y le debió empujar a unirse a los carlistas en $1836^{37}$. Durante la Primera Guerra Carlista dirigió el $6^{\circ}$ batallón de Aragón ${ }^{38}$ y combatió con Cabañero en el ataque a Zaragoza, el 5 de marzo de ese año ${ }^{39}$. Acabada la guerra trató de huir a Francia, pero no pudo conseguirlo y en julio de 1840 se presentó a las autoridades en La Seu d'Urgell (Lérida). Siete años después consiguió que se le reconociera la pensión de invalidez por heridas de guerra, pero esto no le impidió participar en la revuelta de los matiners. Así pues, se rebeló en Fuentes de Ebro (Zaragoza) en abril de 1848, poniéndose al frente de una pequeña partida, con la que cometió varias exacciones por los pueblos. No obstante, no pudo mantenerse en campaña y, ante lo apurada de su situación, se acogió al indulto en Calatayud cuatro meses más tarde ${ }^{40}$.

Además de Aznar también fueron apresados el comandante carlista Rafael Gámez y unos miembros de la milicia nacional, de los que las autoridades también sospechaban $^{41}$. Y se ordenó la detención de Gregorio Puelles, pero éste pudo esconderse en casa de un tal Miguel Villalta, escapando así de sus enemigos ${ }^{42}$. En vista de la gravedad de la situación, el capitán general de Aragón, Ignacio Gurrea, acabó cancelando el viaje que tenía previsto a las Cinco Villas, para poder quedarse en Zaragoza ${ }^{43}$.

Estas detenciones aceleraron la insurrección que se estaba preparando, lo que sorprendió a los carlistas del exilio, que no esperaban tan pronto el alzamiento ${ }^{44}$. De esta manera, en la noche del 21 de mayo se decidió, en una reunión en Zaragoza, adelantar la revuelta en todo Aragón a la noche siguiente, iniciándola así antes que en el resto de España. Acto seguido salieron varios implicados hacia otras partes de la región, para informar del cambio de planes ${ }^{45}$. Otra reunión se celebró en Calatayud, fijándose para la misma noche el comienzo de la rebelión y leyéndose una carta del general Elío, en la que se les comunicaba el dinero y los apoyos con los que podían contar ${ }^{46}$.

\section{La insurrección}

De iniciar el alzamiento se encargó Cipriano de los Corrales, un hidalgo de Meruelo (Cantabria), que había servido en las filas de don Carlos hasta que en 1839 se aco-

\footnotetext{
37 AGMS, primera sección, legajo A-2707.

38 AMC, caja 93.

39 CÓRDOBA, Buenaventura: Vida militar...v. 3, p. 179. PIRALA, Antonio: Historia de la guerra ...v. 5 , p. 54.

40 AGMS, primera sección, legajo A-2707. $D M V, 14$ de junio, 8 de agosto y 11 de septiembre de 1848 . FERRER, Melchor, TEJERA, Domingo y ACEDO, José: Historia del tradicionalismo...v. 19, pp. 161 y 162.

41 ADPZ, gobernación, caja 1210. LL, 22 de mayo de 1855.

42 ADPZ, vigilancia, caja XVI-1189.

$43 L L, 22$ de mayo de 1855.

$44 D M V, 5$ de junio de 1855.

45 LL, 24 de mayo de 1855.

46 ADPZ, vigilancia, caja XVI-1189.
} 
gió al convenio de Vergara, lo que le permitió revalidar su puesto de teniente en el ejército de la reina. Tras servir en varios destinos, en abril de 1854 logró ascender a capitán, siendo entonces destinado al escuadrón de caballería de Bailén, que tenía su acuartelamiento en Zaragoza. Tres meses después participó en el alzamiento progresista contra el gobierno moderado del conde de San Luis, lo que le fue recompensado con el grado de comandante, sólo efectivo a efectos de antigüedad ${ }^{47}$.

El triunfo de este pronunciamiento y tal vez las promesas de sus antiguos compañeros de armas debieron animarle a sublevarse de nuevo, poniéndose a la cabeza de una rebelión legitimista. De esta manera, a las diez de la noche del 22 de mayo se presentó en el cuartel del escuadrón de Bailén en Zaragoza, pretextando que su caballo estaba enfermo. Se puso entonces a jugar a las cartas con los oficiales de servicio, mientras los sargentos implicados dejaban entrar en el cuartel a paisanos armados, entre los que se encontraba Gregorio Puelles. Una vez estuvieron todos dentro, los suboficiales irrumpieron en el cuarto de estandartes, sorprendiendo a los mandos que se encontraban jugando allí. Entonces, el capitán Corrales tomó el control del cuartel, mientras los oficiales eran encerrados en un cuarto y los sargentos daban vivas a Carlos VI, pese a ser muchos de ellos de familia liberal ${ }^{48}$. A continuación los sublevados reunieron a la tropa y leyeron una proclama, en la que justificaban su rebelión por la necesidad de defender la religión (amenazada por la desamortización de Madoz) y el trono (en peligro por la llegada al poder de los progresistas) ${ }^{49}$.

Después de esto, los rebeldes salieron de Zaragoza con los 60 jinetes del acuartelamiento, pertenecientes al escuadrón de Bailén, a las secciones de cazadores de Aragón y a las de Cataluña, más algunos paisanos que se les habían unido ${ }^{50}$. Estos eran, además de Gregorio Puelles, su protector Miguel Villalta, el abogado Rafael Salvador (uno de los principales agentes de la sublevación), el sastre Ramón Villanueva (que había elaborado uniformes para los rebeldes y que había contribuido a esconder los fusiles de la paridera de Mediana), el sacerdote Pedro Minguijón y un tal José Satorres, del que no sabemos casi nada ${ }^{51}$. Todos ellos iban al principio a pie, pero pronto consiguieron caballos en una parada de posta por la que pasaron. Después llegaron a La Muela, donde desarmaron a la pareja de la guardia civil del pueblo, que había rechazado sus propuestas para unirse a la rebelión ${ }^{52}$.

El suceso llegó a oídos de las autoridades gracias a un oficial que pudo escapar del cuartel y avisar de la revuelta al capitán general, a la una de la madrugada ${ }^{53}$. Al conocer estos hechos Ignacio Gurrea movilizó a la milicia y preparó una proclama,

\footnotetext{
47 AGMS, primera sección, legajo C-3438.

48 PIRALA, Antonio: Historia contemporánea... v. 1, p. 672. FERRER, Melchor, TEJERA, Domingo y ACEDO, José: Historia del tradicionalismo... v. 20, pp. 150 y 151. AGA, caja 54 / 5550. LL, 24 de mayo de 1855 .

49 De JAIME, José María y DE JAIME, José: Manuel Marco... pp. 54 y 225-227.

50 PIRALA, Antonio: Historia contemporánea... v. 1, p. 672. LL, 24 de mayo de 1855.

51 ADPZ, vigilancia, caja XVI-1189. LL, 8 de junio de 1855. DMV, 8 de junio de 1855 .

$52 L L, 24$ y 25 de mayo de 1855. $D M V, 6$ de junio de 1855.

$53 L L, 24$ de mayo de 1855. Según Ferrer, fueron los carlistas los que antes de irse liberaron a los oficiales presos, que pudieron así avisar a Gurrea. Pero esto es inverosímil y además no cuadra con el retraso en que se tocó alarma, al menos dos horas después de salir del cuartel los rebeldes. FERRER, Melchor, TEJERA, Domingo y ACEDO, José: Historia del tradicionalismo... v. 20, p. 151.
} 
que hizo pública una hora más tarde, junto con otra del gobernador civil. Además, se comunicó lo sucedido a Madrid, recibiéndose contestación antes de que los rebeldes cortaran el cable del telégrafo. Mientras tanto se iban reuniendo los batallones de la guarnición, a los que el jefe liberal arengó uno por uno poco antes de amanecer. Cuando dispuso de todas sus fuerzas, a las seis de la mañana, salió de Zaragoza en persecución de los rebeldes, a la cabeza de los 400 militares de infantería destinados en la capital aragonesa. Como los rebeldes se habían llevado a toda la caballería del ejército, Gurrea se hizo acompañar de los 50 jinetes de la milicia nacional de la ciudad, para poder perseguir a los carlistas ${ }^{54}$. A estos añadió a los oficiales del cuerpo sublevado (que ya estaban todos en libertad), a fin de contar con un poco más de caballería ${ }^{55}$.

Tampoco el gobierno se quedaba inactivo, pues en cuanto se enteró de la sublevación empezó a tomar medidas. En primer lugar el ministro de la gobernación declaró en estado de guerra a la capitanía general de Aragón $^{56}$, al tiempo que salían para Aragón el regimiento de ingenieros de Guadalajara y la caballería de Farnesio, que se encontraba en Madrid y que estaba dirigida por el brigadier Serrano. Además, se ordenó que fueran pasados por las armas los cabecillas y diezmados los soldados que se aprehendieran ${ }^{57}$.

Mientras esto ocurría se iban produciendo levantamientos en otros lugares. Esa misma noche entraron en Calamocha 15 hombres armados, que desarmaron a los guardias civiles del puesto e hirieron a uno de ellos. Dos horas más tarde abandonaron la villa, llevándose diez caballos y reforzando su partida con cinco voluntarios. Esta acción llevó al gobernador civil de Teruel a salir con fuerzas en su persecución ${ }^{58}$. Después de esto no tenemos más noticia de dicha partida, que probablemente se uniría a las fuerzas que estaba reuniendo uno de los hermanos Marco por la zona.

Otro alzamiento estaba previsto en Catalayud, donde los carlistas pretendían apoderarse del fuerte por sorpresa. Pero un confidente avisó al alcalde y al jefe de la milicia nacional de dicha población, al anochecer del 22 de mayo, diciéndoles que se iba a producir un levantamiento esa misma noche e incluso los nombres de los principales implicados ${ }^{59}$. Esto impulsó a las autoridades a movilizar la milicia y a trasladar allí a la columna de Villanueva, lo que impidió llevar a cabo los planes carlistas. Ante esta situación, un grupo de 25 ó 30 rebeldes salió del pueblo esa misma noche, desarmando a los milicianos que encontraron en el campo, a los que enseguida pusieron en libertad. Cuando a medianoche llegaron a Calatayud los nacionales de El Frasno, otro grupo de 20 comprometidos saltó las tapias y pasó a los huertos para unirse a los que habían salido antes. Una vez se encontraron todos juntos, dieron el grito de ¡Viva Carlos VI! y marcharon a Terrer. Allí esperaron a la partida de Roger, cura de Alarba, al que acompañaban el alcalde y el regidor segundo de dicha población. También se

$54 L L, 23$ de mayo de 1855. PIRALA, Antonio: Historia contemporánea ... v. 1, p. 672. DMV, 26 de mayo de 1855. AGA, caja 54 / 5550. Según Pirala, Gurrea salió de Zaragoza con 600 infantes.

$55 L L, 24$ de mayo de 1855.

56 AGA, caja 54 / 5550. DMV, 26 de mayo de 1855.

$57 L L, 25$ y 26 de mayo de 1855 .

$58 D M V, 29$ de mayo y 6 de junio de 1855 .

59 ADPZ, vigilancia, caja XVI-1189. 
les unió otro grupo, formado en Moros, y que estaba mandado por el sacerdote Benito Marquina. Mientras tanto los liberales de la zona movilizaban sus milicias, como ocurrió en Ateca, donde permaneció de guardia durante toda la noche, aguardando a los carlistas ${ }^{60}$.

Al día siguiente se reunieron en Terrer las tres partidas rebeldes, saliendo todos juntos (en número de cien) hacia Cervera de la Cañada, donde capturaron al recaudador de contribuciones del partido, al que robaron el dinero que llevaba ${ }^{61}$. Luego siguieron a Villarroya de la Sierra, encontrándose allí con la partida del sacerdote Marcelino Millán ${ }^{62}$. Entre todos sumaban 120 hombres $^{63}$, armados con trabucos, carabinas y escopetas, que se pusieron a las órdenes de Manuel Marco. La partida conjunta tomó la dirección de Soria, pero esto debió ser una treta para engañar a sus adversarios, ya que al poco tiempo los carlistas dieron media vuelta, cruzando el río Jalón entre Bubierca y Alhama, en dirección al campo de Bello. Allí planeaban unirse con el otro Marco, que había reunido unos 100 hombres de la ribera del Jiloca ${ }^{64}$. Entre ellos debían encontrarse los 20 ó 30 hombres que se había llevado consigo el secretario del Ayuntamiento de Acered ${ }^{65}$.

Por otra parte, el 23 de mayo se sumaron a la revuelta los 27 jinetes de cazadores de Aragón que se encontraban acantonados en Fuentes de Ebro. Pero en cuanto se disponían a abandonar el pueblo, dirigidos por su sargento, fueron detenidos por los milicianos nacionales, que frustraron así la sublevación ${ }^{66}$. El líder de la revuelta, el sargento F. de Diego, fue conducido a Zaragoza, donde fue fusilado dos semanas después ${ }^{67}$.

Pero volvamos con los sublevados de Zaragoza, que el día 23 habían llegado ya a los alrededores de La Almunia, adonde el capitán Corrales decidió mandar un destacamento. Esta fuerza le informó de que los nacionales del pueblo estaban organizando la defensa, por lo que decidió pasar de largo, haciéndose pasar por tropas del ejército para no ser hostilizado por los defensores. Así pues, y tras hacer un alto para dar de comer a los caballos, continuó su marcha hacia Almonacid de la Sierra. Allí llegó a la una de la tarde y, como su fuerza estaba cansada, decidió darle un descanso de varias horas ${ }^{68}$. Poco después alcanzó a los sublevados un sacerdote procedente de

60 FERRER, Melchor, TEJERA, Domingo y ACEDO, José: Historia del tradicionalismo... v. 20, pp. 152 y 153 . $D M V, 26$ y 30 de mayo de 1855. $L L, 24,25$ de mayo y 3 de junio de 1855 . ADPZ, vigilancia, caja XVI-1189.

$61 D M V, 30$ de mayo de 1855. FERRER, Melchor, TEJERA, Domingo y ACEDO, José: Historia del tradicionalismo... v. 20, pp. 153.

62 ADPZ, vigilancia, caja XVI-1189. FERRER, Melchor, TEJERA, Domingo y ACEDO, José: Historia del tradicionalismo... v. 20, pp. 153.

$63 L L, 25$ de mayo de 1855. Según los papeles conservados en el Archivo General de la Administración, las fuerzas combinadas ascendían a 200 hombres. Archivo General de la Administración, caja 54 / 5550.

$64 L L, 25$ y 26 de mayo de 1855. Según Ferrer, Marco llegó a Terrer en la noche del 23 de mayo para unirse a las fuerzas de Calatayud, pero no pudo encontrarlas y volvió a Munébrega. FERRER. M, TEJERA. D y ACEDO. J: Historia del tradicionalismo... v. 20, p. 153.

65 ADPZ, vigilancia, caja XVI-1189.

$66 \quad L L, 31$ de mayo de 1855.

$67 D M V, 8$ de junio de 1855.

68 PIRALA, Antonio: Historia contemporánea... v. 1, p. 672. FERRER, Melchor, TEJERA, Domingo y ACEDO, José: Historia del tradicionalismo... v. 20, p. 151. LL, 25 de mayo de 1855. CÓRDOBA, Pablo: 
Zaragoza, al que vitorearon y al que pidieron que se uniese a ellos, pero éste respondió diciéndoles que prestaría mejores servicios en el pueblo de María, rechazando así su propuesta ${ }^{69}$.

Poco después los carlistas continuaron la marcha, pero debido a esta parada el general Gurrea pudo alcanzarlos en los alrededores de Alfamén. El jefe liberal se dirigió entonces hacia los rebeldes con los nacionales de caballería y los oficiales, dejando atrás a la infantería que lo acompañaba. Pretendía evitar todo derramamiento de sangre y pensaba que los sublevados se someterían si se les recordaba su deber. Cuál fue su sorpresa cuando fue recibido a tiros y con una carga de caballería, lo que provocó la muerte de dos de sus ayudantes, así como de cinco nacionales de caballería, además de algunos heridos. Por suerte para él, fue rescatado por la guardia civil y los milicianos de infantería que le acompañaban, evitando así que fuera capturado por los sublevados. Después de este revés, Gurrea se retiró a Cariñena, donde tuvo que dar descanso a su tropa (cansada tras 15 horas de marcha), perdiendo así de vista al enemigo. Posteriormente continuó la persecución con la infantería y unos 60 caballos de carabineros y de la guardia civil ${ }^{70}$.

Sin embargo, las cosas no marchaban muy bien para la caballería rebelde, ya que no encontraba fuerzas amigas a las que unirse, por lo que iba un poco desorientada. Además, Gurrea recibió pronto al resto del escuadrón de cazadores de Aragón, con los que continuó persiguiendo a los carlistas $^{71}$. Para acelerar la marcha y escapar de sus enemigos, Corrales ordenó abandonar el carro que transportaba la caja del escuadrón, repartiendo entre sus hombres el dinero que llevaba. Después de esto pasó a Aguarón y, el 24 de mayo, a Cariñena y Paniza. Allí se enteró de que Manuel Marco se encontraba en Acered con 200 infantes y 40 jinetes, procedentes de Calatayud, de la ribera del Jiloca y del campo de Bello, por lo que decidió dirigirse hacia dicho punto $^{72}$.

Por esas fechas el brigadier carlista Francisco García, levantó otra partida en el Maestrazgo aragonés, con voluntarios de la zona ${ }^{73}$. Este cabecilla, nacido en Berge

Historia de don Carlos de Borbón y Este y de su augusta familia desde el convenio de Vergara hasta nuestros días, Madrid, Imprenta de T. Rey, 1870, v. 2, pp. 66 y 67.

69 ADPZ, vigilancia, caja XVI-1189.

$70 D M V, 29$ de mayo de 1855. PIRALA, Antonio: Historia contemporánea... v. 1, p. 673. FERRER, Melchor, TEJERA, Domingo y ACEDO, José: Historia del tradicionalismo... v. 20, p. 151. LL, 25 y 29 de mayo de 1855. ADPZ, vigilancia, caja XVI-1189. AGA, caja 54 /5550. Según la documentación conservada en este archivo, Gurrea sólo perdió a uno de sus ayudantes. Por otra parte, Córdoba afirma que Gurrea atacó a los rebeldes después de instarles a que se rindieran, pero como perdió ocho hombres se justificó diciendo que había sido atacado por sorpresa. Otra versión es la de La Libertad, donde se dice que el 29 de mayo los rebeldes fueron derrotados en Alfamén, algo que es contradicho por las demás fuentes. CÓRDOBA, Pablo: Historia de don Carlos... v. 2, p. 66.

71 FERRER, Melchor, TEJERA, Domingo y ACEDO, José: Historia del tradicionalismo...v. 20, p. 152.

$72 L L, 27$ de mayo de 1855. PIRALA, Antonio: Historia contemporánea ... v. 1, p. 673. DMV, 30 de mayo y 4 de junio de 1855 .

73 ADPZ, vigilancia, caja XVI-1189. LL, 9 de junio de $1855 . \quad$ Ferrer sostiene que la partida se formó en Belchite, con voluntarios de aquel pueblo y alrededores, pero esto es desmentido por las otras fuentes y es poco verosímil, por la distancia entre ese pueblo y La Cerollera. FERRER. M, TEJERA. D y ACEDO. J: Historia del tradicionalismo... v. 20, p. 154. 
(Teruel) $)^{74}$ hacia $1799^{75}$, fue capitán de realistas durante el Trienio, combatiendo en esa época en la partida del Royo. Acabada la guerra sirvió en el regimiento de guardias valonas a las órdenes de Carnicer ${ }^{76}$, pasando después a los voluntarios realistas, en los que desempeñó el empleo de teniente ${ }^{77}$. Cuando se disolvió el cuerpo debió unirse a los carlistas, combatiendo primero con Forcadell ${ }^{78}$, acompañando luego a Cabrera y a Carnicer en sus viajes a Navarra para entrevistarse con el pretendiente ${ }^{79}$.

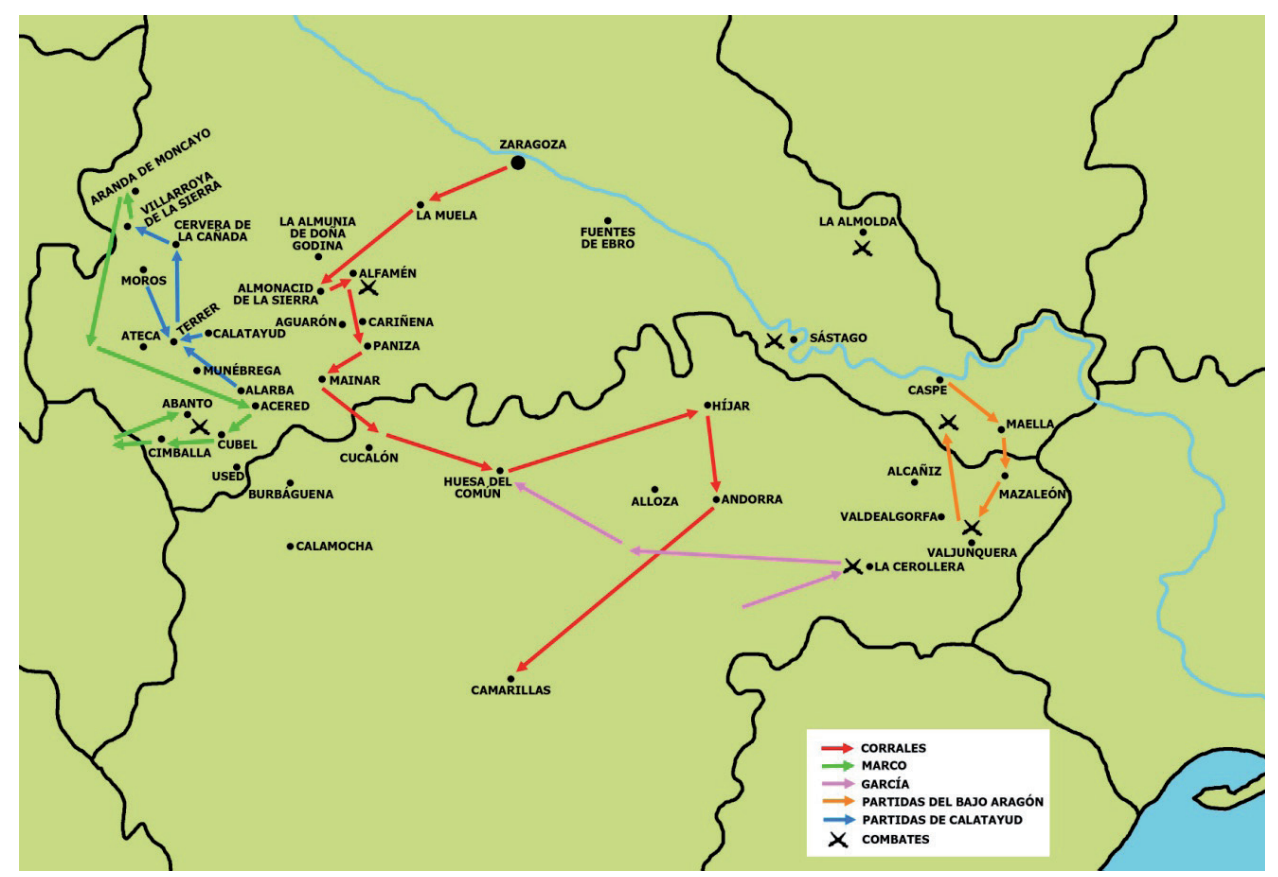

Fig. 1. Movimientos carlistas en mayo de 1855.

Tras el segundo viaje fue capturado por los liberales, pero en enero de 1836 fue liberado ${ }^{80}$ y en octubre del año siguiente, siendo ya coronel, recibió el mando del batallón de guías de Aragón. Al frente de esta unidad tomó parte en el ataque contra Zaragoza, a las órdenes de Cabañero, el 5 de marzo de 1838. Su actuación debió ser del agrado de sus superiores, ya que en julio era jefe de brigada y estaba al mando de los batallones de guías, $4^{\circ}$ y $6^{\circ}$ de Aragón, con los que participó en las operaciones para la defensa de Morella. Más tarde, el 1 de octubre, mandó el ala derecha

\footnotetext{
74 RÚJULA, Pedro: Rebeldía campesina y guerra civil en Aragón, 1821-1834, Zaragoza, Universidad de Zaragoza, 1994, p. 990.

75 ADPO, legajo 4 M 593. ADA, legajo 4 M 195.

76 CÓRDOBA, Buenaventura: Vida militar...v. 1, pp. 121 y 343.

77 ROLDÁN, Enrique: Estado mayor general carlista en las tres guerras del siglo XIX, Madrid, Editorial Actas, 1998. p. 50.

78 RÚJULA, Pedro: Rebeldía campesina y guerra civil... pp. 990 y 996.

79 CÓRDOBA, Buenaventura: Vida militar...v. 1, pp. 101-118, 121 y 341-343.

80 CÓRDOBA, Buenaventura: Vida militar...v. 1, pp. 341-343.
} 
carlista en la batalla de Maella, arrollando a las tropas cristinas por dicho costado ${ }^{81}$. Acabada la guerra emigró a Francia con su mujer, con el rango de brigadier, siendo confinado en Bourg-en-Bresse (Ain) por las autoridades francesas ${ }^{82}$. Poco después se estableció en Pau (Pirineos Atlánticos), donde vivió de un pequeño subsidio que le daba el gobierno francés ${ }^{83}$. No obstante, parece que esta ayuda era insuficiente para llevar una vida digna, por lo que regresó a España y trató de participar en la revuelta de los matiners. Pero no le fueron bien las cosas, por lo que tuvo que presentarse al indulto en el otoño de $1848^{84}$.

Siete años más tarde Francisco García se alzó de nuevo en armas, como he dicho anteriormente. En esta ocasión reunió una fuerza de 22 hombres, que fue derrotada y dispersada el 25 de mayo en La Cerollera, siendo capturado el caballo que montaba el líder rebelde. Dos días más tarde, el cabecilla Joaquín Rollo, al que se había encargado la sublevación de los pueblos de la ribera del Ebro, fue fusilado por la columna del Bajo Aragón, al mando del coronel Mateo, en las cercanías de Sástago ${ }^{85}$.

En cuanto a Corrales, se hallaba en una situación delicada, pues algunos de sus hombres empezaban a abandonarle, ya que se les había obligado a sumarse a una rebelión con la que no estaban de acuerdo. Los primeros que desertaron fueron dos cabos, que lo hicieron en Almonacid el 23 de mayo y se entregaron en La Almunia al día siguiente, diciendo a las autoridades que sus compañeros se hallaban muy desalentados. A estos les siguieron un cabo y cinco soldados en Moyuela, un cabo y siete soldados más en Almonacid, así como varios más en Ricla y otros puntos. El jefe carlista intentó contrarrestar estas deserciones ofreciendo seis reales diarios a todo aquel que se le uniera, pero no consiguió nada con ello, pues era evidente para todos que ese alzamiento no tenía futuro ${ }^{86}$. Pese a ello, Corrales seguía apoderándose de los caudales públicos de los pueblos por los que pasaba ${ }^{87}$, esperando así tener más recursos para reclutar soldados. Mientras tanto, había cuatro columnas del ejército persiguiendo a los carlistas, que no hacían más que huir del acoso al que los sometía su enemigo ${ }^{88}$.

La mejor opción para el jefe rebelde era intentar unirse a las fuerzas de Marco, para lo cual se puso en marcha hacia el suroeste. Pero parte de su fuerza fue alcanzada en una corraliza, el 25 de mayo, por las tropas de la reina. Fueron entonces capturados dos sargentos, un cabo y cuatro soldados, aunque los primeros llevaban ya puestas las insignias de tenientes de Carlos VI. Se trataba de Francisco Burgos y Felipe Mir, que habían destacado en la organización del levantamiento, intentando convencer a algunos soldados para que se unieran al mismo. Por esta razón, y

81 CÓRDOBA, Buenaventura: Vida militar...v. 3, pp. 81, 82, 179, 300, 305, 350 у 390.

82 ADPO, legajo 4 M 593. DMV, 2 de septiembre de 1840.

83 ADA, legajos 4 M 194, 4 M 196 y 4 M 199.

$84 D M V, 13$ de diciembre de 1848 .

$85 D M V, 29$ y 31 de mayo de 1855. CÓRDOBA, Pablo: Historia de don Carlos... p. 67.

$86 L L, 25,26,27$ y 28 de mayo de 1855 . DMV, 29 y 30 de mayo de 1855. ADPZ, vigilancia, caja XVI1189.

87 LL, 28 de mayo de 1855. CÓRDOBA, Pablo: Historia de don Carlos... v. 2, p. 69.

88 LL, 28 de mayo de 1855. PIRALA, Antonio: Historia contemporánea... v. 1, p. 673. 
de acuerdo con las órdenes recibidas del gobierno, fueron fusilados en Mainar al frente de la tropa ${ }^{89}$.

Tras este revés Corrales trató de pasar el Jiloca por Burbáguena, pero no lo consiguió por haberse interpuesto Gurrea en Cucalón ${ }^{90}$. Esto no le dejó más opción que dirigirse hacia el Este, para unirse con los insurrectos que operaban por esa parte de Aragón. De esta manera, el 27 de mayo se encontró con las fuerzas de García en Huesa del Común, de donde salieron juntos al día siguiente hacia Alloza ${ }^{91}$. A una hora de dicho pueblo fueron avistados por la columna del coronel Mateo, lo que les obligó a acelerar el paso, abandonando por el camino varios caballos cansados y sustituyéndolos por otros que encontraban en su marcha. El jefe liberal los persiguió durante doce horas, pero como llovía y no tenía caballería, tuvo que dar a la tropa un pequeño descanso en la venta de la Pobleta, perdiendo así de vista a los carlistas $^{92}$. Poco después llegaban estos a Híjar, donde fueron derrotados el 29 de mayo por la columna de Mateo, que los hizo huir en dirección a Andorra ${ }^{93}$.

Tampoco le iban bien las cosas a Marco, que estaba siendo perseguido por Serrano y por el gobernador de Teruel, este último con 150 hombres $^{94}$. Esta amenaza le llevó a marchar a Cubel y a Cimballa, para pasar después a Castilla, huyendo de la persecución enemiga y alejándose de las fuerzas de Corrales ${ }^{95}$. Y aunque enseguida regresó a Aragón, fue alcanzado a una legua de Abanto, a las dos de la tarde del 28 de mayo, por la columna de Serrano. En esta ocasión los carlistas se situaron en un sitio bastante escarpado para defenderse mejor, pero esto no impidió que fueran atacados y puestos en fuga por las tropas de la reina. Tras este encuentro los rebeldes se dispersaron y fueron perseguidos también por la columna de Thomas, que aumentó aún más sus bajas. En total dejaron en manos de sus enemigos 30 prisioneros, 60 armas de fuego, ocho lanzas, un tambor, una caja de guerra y muchas municiones, capas y mantas. A continuación Serrano envió al regimiento de caballería de Farnesio, dividido en pequeñas secciones, a perseguir a los fugitivos, pero la escabrosidad del terreno facilitó su fuga ${ }^{96}$. Sin embargo, como consecuencia de este desastre la facción se disolvió en grupos muy pequeños (de menos de cinco hombres), que fueron perseguidos por las milicias nacionales de Calatayud, La Almunia y Ricla. Y los que no fueron capturados enseguida se acogieron al indulto que dictó la reina el 30 de mayo ${ }^{97}$. De esta manera, las facciones de la zona se desintegraron y Marco tuvo que atravesar toda España para buscar refugio en Portugal. Una vez allí, don Carlos agradeció sus servicios ascendiéndolo a coronel ${ }^{98}$.

\footnotetext{
$89 L L, 28$ de mayo de 1855. DMV, 30 y 31 de mayo de 1855.

90 PIRALA, Antonio: Historia contemporánea... v. 1, p. 672. LL, 28 de mayo de 1855.

91 LL, 31 de mayo de 1855. FERRER, Melchor, TEJERA, Domingo y ACEDO, José: Historia del tradicionalismo... v. 20, p. 154.

$92 L L, 31$ de mayo de 1855.

$93 D M V, 30$ de mayo de 1855. LL, 3 de junio de 1855. CÓRDOBA, Pablo: Historia de don Carlos... v. 2, pp. 68 y 69. PIRALA, Antonio: Historia contemporánea... v. 1, p. 673.

$94 D M V, 30$ de mayo de 1855. LL, 27 de mayo de 1855.

95 FERRER, Melchor, TEJERA, Domingo y ACEDO, José: Historia del tradicionalismo... v. 20 , p. 154.

$96 L L, 29$ y 30 de mayo de 1855. DMV, 31 de mayo, 1 y 4 de junio de 1855.

97 ADPZ, vigilancia, caja XVI-1189. LL, 31 de mayo y 2 de junio de 1855.

98 FERRER, Melchor, TEJERA, Domingo y ACEDO, José: Historia del tradicionalismo... v. 20, p. 155.
} 
Una vez liquidado este foco rebelde, las autoridades dirigieron su atención al Bajo Aragón, donde acababa de formarse una nueva facción. Uno de los jefes de este movimiento carlista era Juan Bautista Pellicer, nacido en Caspe ${ }^{99}$ hacia 1791 y que era un veterano de la Primera Guerra Carlista. En 1834 había sido el líder de una pequeña partida ${ }^{100}$, tres años más tarde se le dio el mando del $5^{\circ}$ batallón de Aragón ${ }^{101}$ y acabó la guerra como vocal de la junta carlista ${ }^{102}$. Entonces emigró a Francia con el rango de coronel ${ }^{103}$, siendo confinado en Thoissey (Ain) por las autoridades galas, que le dieron un subsidio de 70 francos mensuales para que pudiera subsistir con su familia, ya que tenía una herida de bala en la ingle, que le impedía trabajar. Pero estos socorros le fueron retirados en diciembre de 1846, lo que dejó a Pellicer en una situación muy difícil y le llevó a acogerse a una amnistía para poder regresar a España ${ }^{104}$. Sin embargo, allí no debió mejorar mucho su situación, ya que posteriormente se alzó en armas de nuevo, aunque acabó acogiéndose al indulto con toda su partida, en octubre de $1848^{105}$. No obstante, no quiso ingresar en el ejército isabelino y durante un tiempo se dedicó a regentar un molino ${ }^{106}$.

Con más de 60 años, Pellicer decidió tomar de nuevo las armas y, junto a un tal José Sirera y otros 10 ó 12 hombres, convocó a todos los antiguos combatientes carlistas de Caspe el 28 de mayo de 1855, declarando en un bando que los tratarían como desertores en tiempo de guerra si no tomaban las armas y se unían a ellos antes de una hora. El ayuntamiento no pudo hacer nada para impedirlo al no tener fuerza armada, ya que los milicianos estaban desarmados y huyeron en cuanto empezó el alzamiento. Además, en dicho pueblo el carlismo contaba con la simpatía de parte de la población, lo que hizo que al poco tiempo los rebeldes contaran con 150 hombres. Estos combatientes, armados con escopetas, trabucos y carabinas, empezaron a vitorear a Carlos VI y a dar gritos contra Isabel II ${ }^{107}$. Una vez reunida esta fuerza los carlistas se pusieron en marcha hacia Maella, donde se les unió el cura de la localidad, así como algunos voluntarios. A continuación pasaron por Mazaleón, donde consiguieron más reclutas, dirigiéndose después a los alrededores de Alcañiz y uniéndoseles allí algunas partidas comprometidas, con las que pasaron a Valdealgorfa ${ }^{108}$.

La única fuerza liberal que patrullaba la zona era la columna del Maestrazgo, que acababa de llegar de Morella y que el 29 de mayo alcanzó, frente a Valjunquera, a estas facciones, que habían reducido su fuerza a 110 infantes y 8 jinetes. También esta vez los rebeldes fueron derrotados, pero el combate debió ser muy breve, ya que sólo

\footnotetext{
99 PIRALA, Antonio: Historia contemporánea... v. 3, p. 54.

100 RÚJULA, Pedro: Rebeldía campesina y guerra civil... p. 984.

101 CABELLO, Francisco, SANTA CRUZ, Francisco y TEMPRADO, Ramón María: Historia de la guerra última en Aragón y Valencia, Zaragoza, Institución Fernando el Católico y Diputación de Zaragoza, 2006, pp. 258 y 349.

$102 D M V, 14$ de febrero de 1840.

103 ADPO, legajo 4 M 593.

104 ADA, legajos 4 M 194 y 4 M 202.

$105 D M V, 14$ de octubre y 26 de noviembre de 1848 .

106 PIRALA, Antonio: Historia contemporánea... v. 3, p. 54.

107 ADPZ, vigilancia, caja XVI-1189.

108 LL, 31 de mayo de 1855. PIRALA, Antonio: Historia contemporánea... v. 1, p. 673. FERRER, Melchor, TEJERA, Domingo y ACEDO, José: Historia del tradicionalismo... v. 20, p. 154.
} 
tuvieron un muerto. En dicho encuentro fue capturado el fraile exclaustrado Silvestre Buisán, capellán de Caspe, junto con un tal Ignacio Maranillo, siendo los dos pasados por las armas a las 5 de la tarde de ese día ${ }^{109}$.

Mientras tanto Gurrea se ponía en marcha hacia Alcañiz, adonde llegó el 30 de mayo a las cuatro de la tarde. También pasaron a esa zona otras cuatro columnas liberales (las de Aguirre, Serrano, Mateo y Pieltain), que intensificaron la persecución de los carlistas. Estos estaban cada vez más desmoralizados, como muestra el hecho de que en Caspe se habían presentado 39 de ellos al indulto ${ }^{110}$. A esto se añadía que no encontraban apoyo en los pueblos de la zona, que se sentían poco inclinados a la guerra y que no los reforzaban con voluntarios. De hecho, sólo salieron a campaña una octava parte de los que tenían previsto, lo que se debía en parte a la falta de un jefe de prestigio. Por eso vagaban en pequeños grupos, mientras esperaban la llegada de Gamundi, en quien tenían gran confianza. Al mismo tiempo la milicia nacional de los pueblos, aunque desarmada, estaba aprehendiendo a los dispersos, que diariamente cogía en varios puntos y que luego entregaba a la autoridad militar, que a su vez los ejecutaba. En una de las batidas los liberales encontraron, en un paraje de los puertos de Beceite, varias armas enterradas y gran cantidad de municiones envueltas en números del diario La Esperanza $a^{111}$.

Una vez en Alcañiz, Gurrea envió a cinco pequeñas columnas contra los sublevados del Bajo Aragón. Estos consiguieron escapar a Valcomuna sin ser vistos, pero tropezaron con dos fuerzas liberales y tuvieron que retirarse al azud de Caspe. Allí sufrieron una completa derrota el 31 de mayo, a manos del coronel Salcedo, quien les causó bastantes muertos. Además de esto, les cogió varias armas, pertrechos y otros efectos, matando a dos de sus jefes, mientras casi todos los supervivientes se presentaban al indulto. Entre ellos se encontraban los cabecillas Agustín Mora (que había sido factor de la división carlista de Aragón en la guerra anterior ${ }^{112}$ ), José Sirera, Matías Albiac, Juan Bautista Pellicer y Bernardino Cortés. A los últimos Gurrea les comunicó que libraría de la muerte a los carlistas que se presentaran en lo sucesivo. No podía hacer más por ellos, ya que muchos de los rebeldes eran militares y tenían que someterse a un consejo de guerra. Mientras tanto, todos los demás prisioneros permanecían en las cárceles hasta que se decidiera quiénes quedaban comprendidos en el perdón ${ }^{113}$.

Pero la lucha contra el carlismo se resolvía también en otros frentes. El 28 de mayo fue detenido por la guardia civil de Huesca un jefe carlista llamado San Martín, del que se sospechaba que estaba preparando una partida por la zona. Después de eso se empezó a buscar los fusiles que se sospechaba que tenía escondidos en la Sierra Alta,

\footnotetext{
$109 L L, 31$ de mayo y 1 de junio de 1855.

$110 L L, 31$ de mayo y 2 de junio de 1855. DMV, 8 de junio de 1855. PIRALA, Antonio: Historia contemporánea... v. 1, p. 673. FERRER, Melchor, TEJERA, Domingo y ACEDO, José: Historia del tradicionalismo... v. 20, p. 154.

$111 D M V, 3$ y 5 de junio de 1855. ADPZ, vigilancia, caja XVI-1189.

112 CÓRDOBA, Buenaventura: Vida militar...v. 1, p. 231.

$113 L L, 3$ y 4 de junio de 1855. DMV, 1, 3, 4, 6, 8 y 10 de junio de 1855. ADPZ, gobernación, caja 1210 y vigilancia, caja XVI-1189. PIRALA, Antonio: Historia contemporánea... v. 1, p. 673. FERRER, Melchor, TEJERA, Domingo y ACEDO, José: Historia del tradicionalismo...v. 20, pp. 154 y 155.
} 
pero sin encontrar nada ${ }^{114}$. También al norte del Ebro operaba el cabecilla Mariano Nicolás, que recorría con algunos hombres los pueblos de la zona, hasta que fue deshecho por los nacionales de La Almolda, que le hicieron dos prisioneros ${ }^{115}$.

Mientras tanto no dejaban de llegar detenidos al castillo de La Aljafería, en Zaragoza. A finales de mes ya había allí 48 hombres y 4 mujeres, debido a su participación en la conjura carlista. El más importante era José Pueyo, que había sido detenido el 26 de mayo en la capital aragonesa, al descubrirse que era uno de los principales jefes de la conspiración. Dos días después fueron apresadas ocho personas en el número 189 de la calle del Azogue (en Zaragoza) por sospecharse que reclutaban allí soldados para los carlistas. Uno de ellos, llamado Vidal, opuso resistencia e intentó fugarse, pero fue al final reducido. Más tarde se capturó a Miguel Villalta y a Ramón Villanueva, que aunque iban con la caballería rebelde habían caído en manos de las autoridades y fueron conducidos presos a los depósitos municipales. Lo mismo le pasó al alcalde de Almonacid, que fue apresado el 30 de mayo. Por último, podemos citar a Pablo Duarte, un sastre de Zaragoza detenido bajo la acusación de haber cosido varias blusas para la facción ${ }^{116}$.

Por otra parte, el arzobispo de Zaragoza hizo pública una pastoral el 2 de junio, pidiendo obediencia y respeto a las autoridades y ordenando a los curas de la archidiócesis que la leyeran en sus parroquias. Al día siguiente el comandante militar de Daroca hizo prender a José Satorres y al abogado Rafael Salvador, que tras haber salido de Zaragoza con la caballería sublevada, se habían refugiado en aquella población ${ }^{117}$. Además, el alcalde de Híjar, gracias a la mediación de su colega de La Puebla, consiguió que se presentaran, con armas y caballos, diez jinetes sublevados que iban por las inmediaciones. Poco después se fueron presentando todos los paisanos rebeldes que habían salido de Samper de Calanda ${ }^{118}$.

Mientras tanto, el grupo dirigido por Corrales y García, se iba retirando hacia Camarillas, acosado por la columna de Pieltain, que llegó a perseguirla durante 13 horas, el 31 de mayo. Pero los carlistas lograron darle esquinazo y eludir de momento a las otras tres columnas que iban detrás de ellos, al dar media vuelta y encaminarse hacia Aguaviva. Sin embargo, fueron alcanzados en la cuesta de las Parras, cerca de dicha localidad, por las fuerzas del brigadier Thomas, el día 5 de junio. Éste les atacó y les capturó 10 jinetes, así como monturas, armas y tres cargas de equipo, continuando luego su persecución hasta el santuario de la virgen de la Balma, a tres leguas de allí. Los supervivientes se dividieron entonces en dos grupos, uno dirigido por Corrales, formado por 24 jinetes salidos de Zaragoza, y otro mandado por García, que contaba con 30 ó 40 hombres ${ }^{119}$.

El primero de ellos, tras una marcha increíble, cruzó el Ebro en la madrugada siguiente por la barca de Fayón, abandonando así Aragón. Sus integrantes continuaron

\footnotetext{
114 ADPZ, vigilancia, caja XVI-1189.

$115 L L, 4$ de junio de 1855. DMV, 6 de junio de 1855.

116 ADPZ, vigilancia, caja XVI-1189. LL, 2 de junio de 1855.

$117 L L, 3$ y 8 de junio de 1855 . $D M V, 8$ de junio de 1855.

118 ADPZ, vigilancia, caja XVI-1189. $L L, 8$ de junio de 1855. DMV, 10 de junio de 1855.

$119 L L, 8$ de junio de 1855. DMV, 10 y 12 de junio de 1855. ADPZ, vigilancia, caja XVI-1189. PIRALA, Antonio, Historia contemporánea... v. 1, p. 673.
} 
la marcha por Cataluña, pero en el pueblo de Sacroca fueron atacados por la columna de Guadalajara, que les mató un corneta y dos caballos, haciendo prisionero al hijo del jefe carlista. A continuación el comandante general de la provincia de Lérida y los nacionales de Mayals salieron en persecución de los rebeldes, a los que cogieron algunos prisioneros e hicieron varios muertos, con tan sólo un herido. Durante la noche siguiente el jefe liberal dio una batida, derrotando de nuevo a sus enemigos. Estos no encontraban ningún apoyo en la zona y continuaban retirándose, mientras se movilizaban las milicias de la provincia ${ }^{120}$.

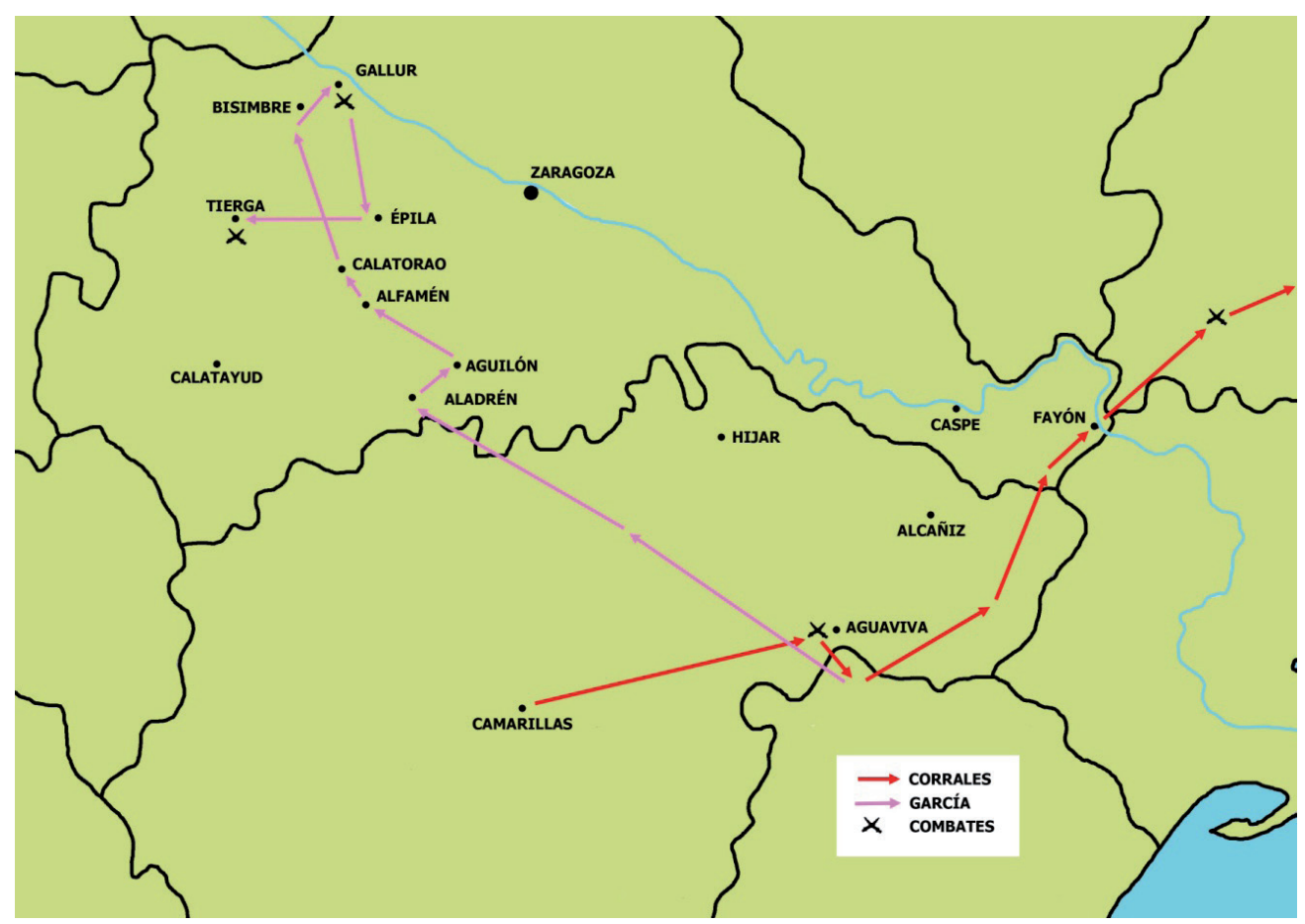

Fig. 2. Movimientos carlistas en junio de 1855.

La persecución mermó considerablemente las fuerzas rebeldes y llevó a Corrales a entregarse en Agramunt (Lérida), a las 7 de la mañana del 7 de junio. Con él iban un sargento y algunos soldados de los sublevados de Zaragoza, así como Gregorio Puelles y un paisano de Calatayud. Ya sólo quedaban algunos dispersos, que fueron perseguidos por el gobernador militar de Lérida hacia Munelar. Este grupo, formado por 10 hombres, perdió a seis de sus integrantes cerca de Pons, al ser capturados por el somatén del pueblo y la guardia civil ${ }^{121}$.

\footnotetext{
$120 L L, 9$ de junio de 1855.

$121 L L, 9$ y 11 de junio de 1855. DMV, 10 de junio de 1855.
} 
Al día siguiente, también a las 7 de la mañana, el capitán Corrales fue fusilado en Agramunt, junto con Gregorio Puelles y el sargento primero Nicolás Enríquez ${ }^{122}$, siendo los soldados llevados presos a la Aljafería, en Zaragoza ${ }^{123}$. En cuanto a García, su fuerza se encontraba bastante desalentada. Esto se debía, además de a las continuas derrotas, a que Gurrea había inducido a las mujeres, madres y hermanas de los que la formaban (naturales de Alloza, Calanda, Andorra y otros pueblos de la zona) a que fueran a exhortar a sus parientes a que volvieran a sus hogares. A esto se añadía el acoso a que era sometida por las cinco o seis columnas liberales que iban en su persecución. Por ello no pudo impedir que se presentasen en Castellote varios oficiales y soldados de su partida, disminuyendo así sus fuerzas ${ }^{124}$.

Por esas fechas ya se habían presentado 200 carlistas al indulto al general Gurrea ${ }^{125}$, lo que le llevó, el 8 de junio, a declarar pacificado Aragón. Pero la revuelta aragonesa, aunque moribunda, aún no estaba concluida. Un grupo de 24 jinetes (que debía ser el dirigido por García) llegó hasta Aladrén, donde pernoctó en la noche del 7 al 8 de junio, pasando al día siguiente por Aguilón y Alfamén, perseguido por las milicias nacionales y por la guardia civil de la zona. Posteriormente llegaron a Calatorao, lo que motivó la salida de los nacionales de dicho pueblo, así como de Ricla y La Almunia. Huyendo de dichas fuerzas los carlistas pasaron el Jalón y se dirigieron hacia los montes de Plasencia. El 9 de junio se les vio por el término de Bisimbre, lo que llevó a salir en su búsqueda a las milicias de Mallén y de Magallón, que no pudieron encontrarlos ${ }^{126}$. Esto se debía a que los rebeldes habían marchado hacia Gallur, por cuyo punto intentaron pasar el Ebro. Pero fueron rechazados por los nacionales del pueblo y algunos carabineros, por lo que se vieron obligados a retirarse ${ }^{127}$. Poco después llegaron al santuario de Ródenas (en Épila), de donde tuvieron que marcharse apresuradamente, al ver la fuerza que se concentraba contra ellos. Perseguidos por los carabineros y por las milicias de Arándiga y Mesones llegaron a Tierga al día siguiente, siendo por entonces 17 jinetes y 3 infantes. Allí abandonaron los caballos para cruzar el río Insuela con dirección a Huesca, pero fueron alcanzados por los nacionales de Brea, que capturaron a doce soldados y a un jefe. De los demás sólo se salvó uno, ya que cuatro cayeron en manos de los liberales y dos se presentaron al indulto con armas y caballos ${ }^{128}$. Con esta acción terminó definitivamente la revuelta carlista de Aragón, que sólo había durado 19 días.

¿Y qué pasó con Francisco García? Pues acabó quedándose sólo con su secretario $^{129}$, por lo que decidió ocultarse, probablemente en casa de algún amigo, para eludir la persecución enemiga. Así permaneció durante varios meses, sin que nadie

$122 L L, 11$ de junio de 1855. DMV, 12 y 13 de junio de 1855. PIRALA, Antonio: Historia contemporánea... v. 1 , pp. 673 y 675 .

${ }_{123} D M V, 25$ de junio de 1855 .

124 LL, 9 de junio de 1855. PIRALA, Antonio: Historia contemporánea... v. 1, p. 673.

$125 D M V, 13$ de junio de 1855.

126 ADPZ, vigilancia, caja XVI-1189.

$127 D M V, 15$ de junio de 1855. PIRALA, Antonio: Historia contemporánea... v. 1, p. 675.

$128 D M V, 15$ de junio de 1855. ADPZ, vigilancia, caja XVI-1189 PIRALA, Antonio: Historia contemporánea... v. 1, p. 675.

129 PIRALA, Antonio: Historia contemporánea ... v. 1, p. 673. 
conociera su paradero, hasta que el 21 de octubre, cansado de su reclusión, acabó presentándose al capitán general de Aragón ${ }^{130}$.



Fig. 3. Bando del general Gurrea declarando el fin de la revuelta.

Una vez aplastada la rebelión hubo que decidir qué se hacía con los 167 prisioneros que se encontraban en la Aljafería y que habían sido traídos de muchos pueblos de Aragón. Los 29 soldados que estaban allí fueron indultados el 18 de junio ${ }^{131}$, librándose así de ser diezmados, como se había ordenado en un principio. A cambio se les obligó a pasar diez años en el ejército de ultramar, alargando así su servicio militar y separándolos de sus familias. Peor lo pasaron los dirigentes del alzamiento, ya que un día después fue fusilado Juan Hernando, cabecilla capturado por los nacionales de Brea la semana anterior. A dicho jefe le siguieron los sargentos prisioneros, que sufrieron la misma suerte el 21 de junio ${ }^{132}$. Y en julio 80 carlistas, la mayoría antiguos sublevados del regimiento de Bailén, fueron conducidos a ultramar, donde pagarían

$130 D M V, 26$ de octubre de 1855. PIRALA, Antonio: Historia contemporánea... v. 1, p. 675.

131 ADPZ, vigilancia, caja XVI-1189. DMV, 25 de junio de 1855.

$132 D M V, 21$ y 25 de junio de 1855. PIRALA, Antonio: Historia contemporánea... v. 1, p. 675. 
sus culpas. Entre ellos se encontraba Marcelino Millán, que fue indultado por Espartero, a disgusto del pueblo zaragozano ${ }^{133}$.

Los que salieron mejor parados fueron los cabecillas que se entregaron al frente de su partida, como Juan Bautista Pellicer y Sebastián Cortés, que vieron por ello suavizada su condena, ya que sólo se les castigó con el destierro en Villarroya de los Pinares (Teruel). Y también los que fueron detenidos antes de estallar la sublevación, a los que en general se les aplicó el mismo castigo. Fue el caso de José Bello, que fue desterrado a Trujillo (Cáceres) y de Rafael Gámez, también comandante, que tuvo que marchar a Ávila ${ }^{134}$.

\section{Conclusiones}

Así acabó el episodio de 1855, del que podemos extraer varias conclusiones. En primer lugar la continuidad entre la revuelta de ese año y el carlismo anterior, al mantenerse el alzamiento carlista en las mismas zonas y, en gran parte, con los mismos jefes. En este sentido, resulta bastante interesante la coincidencia geográfica de las zonas rebeldes en ambos conflictos. En Zaragoza, por ejemplo, ya se había producido una conspiración carlista en febrero de 1834, que al fracasar llevó a los rebeldes en centrarse en la guerra de guerrillas. De los otros centros rebeldes destacan el Bajo Aragón y las comarcas de Daroca y Calatayud, que durante la guerra anterior habían sido las zonas más carlistas de Aragón ${ }^{135}$. En cuanto al Maestrazgo aragonés, fue mucho más débil que los anteriores, pues ya durante la guerra carlista había sido una zona con menos peso del carlismo ${ }^{136}$. Si en esta ocasión se formó allí una partida se debió a la acción de Francisco García, importante jefe de la guerra anterior, que al residir en Berge podía contar con el apoyo de sus amigos y excompañeros de armas.

Por el contrario, en las zonas de Aragón dónde la contrarrevolución había tenido muy poca importancia, como la provincia de Huesca o la comunidad de Teruel, no llegó a producirse ningún alzamiento carlista en 1855. Esto nos muestra que las causas de que la rebelión de ese año se produjera en esas zonas no hay que buscarlas en algo sucedido poco antes, sino que hay que remontarse mucho más atrás. Probablemente a lo sucedido durante la Primera Guerra Carlista o incluso durante el Trienio Liberal, que es cuando se fueron generando las adscripciones políticas a cada uno de los bandos. Después de la guerra de los siete años, aunque el carlismo fue perdiendo fuerza, mantuvo algunos partidarios en las zonas en las que había sido fuerte anteriormente.

Otro aspecto interesante es la extracción de los jefes principales, ya que muchos eran antiguos jefes de la guerra de los siete años. De hecho, en las cuatro zonas en las

133 DMV 14 de julio de 1855. PIRALA, Antonio: Historia contemporánea ... v. 1, p. 675. FERRER, Melchor, TEJERA, Domingo y ACEDO, José: Historia del tradicionalismo... v. 20, p. 157.

134 ADPZ, gobernación, caja 1210.

135 RÚJULA, Pedro: Contrarrevolución. Realismo y carlismo en Aragón y el Maestrazgo, 1820-1840, Zaragoza, Prensas Universitarias de Zaragoza, 1998, pp. 186, 187 y 381.

136 Durante la Primera Guerra Carlista no se creó ninguna partida autóctona en el Maestrazgo aragonés. CARIDAD, Antonio: El carlismo... pp. 640-644. 
que el alzamiento fue importante (Zaragoza, Calatayud, Bajo Aragón y Maestrazgo) operó algún líder veterano de la guerra anterior que era siempre el que ejercía el mando de las operaciones en la comarca. De todos ellos el que menos había destacado durante la guerra anterior era Cipriano de los Corrales, que al ser sólo teniente había pasado muy desapercibido durante el conflicto. Pero el hecho de que se acogiera al convenio de Vergara le permitió mantener su puesto en el ejército liberal, lo que le permitió tener un papel protagonista en el alzamiento de 1855 .

En cuanto a los demás participantes en la revuelta, tenemos poca información sobre ellos, pero probablemente su adhesión al carlismo no fuera algo reciente, dada su amistad con conocidos carlistas o su residencia en zonas donde este movimiento había sido importante. Lo más probable es que hubieran tenido alguna participación en la Primera Guerra Carlista, aunque desde un puesto poco importante, lo que ha hecho que no aparezcan en las fuentes que nos hablan de dicho conflicto. Lo que sí que parece claro es que el carlismo de 1855 bebía mucho del pasado y, salvo unos pocos militares atraídos con promesas de ascensos, era incapaz de atraerse a nuevos partidarios o de difundirse por nuevos territorios.

Al mismo tiempo, el rápido fracaso de estas intentonas demostró que el carlismo no contaba con apoyos suficientes para desencadenar una nueva guerra civil $1^{137}$. Pero eso no significa que hubiera desaparecido. De hecho, resulta llamativo que 15 años después del fin de la Primera Guerra Carlista, todavía quedaran en Aragón personas dispuestas a sublevarse por la causa del pretendiente y que creyesen, además, que esos alzamientos tenían alguna posibilidad de triunfar. Más sorprendente fue la adhesión de algunos militares, que se unieron con sus tropas a la causa tradicionalista, algo inédito hasta entonces. En este sentido, Aróstegui sostiene que con las revueltas de 1855 el carlismo empezó a abandonar su vieja táctica de guerrillas rurales para intentar conseguir adhesiones en el ejército y en las clases más elevadas. Esto continuó en los años siguientes y llevó al alzamiento de Sant Carles de la Ràpita (en 1860) que intentó asemejarse a un típico pronunciamiento liberal, pero que acabó en un fracaso aún más estrepitoso ${ }^{138}$.

Más importante fue el apoyo del clero, ya que 13 eclesiásticos colaboraron con los carlistas y siete de ellos incluso se sumaron a la revuelta ${ }^{139}$. Sin embargo, salvo en algunas localidades, el apoyo popular al movimiento rebelde fue escaso, por lo que no se pudo reunir un número importante de voluntarios. Por lo visto, los campesinos no tenían buenos recuerdos de la guerra, que todavía estaba reciente y que había dejado tras de sí un rastro de muerte y de destrucción. Ni tampoco de los carlistas, que no habían solucionado ninguno de sus problemas y que a menudo se habían comportado como simples bandoleros. Además, desde 1845 los precios agrícolas estaban experimentando un rápido ascenso ${ }^{140}$, lo que reducía la pobreza agraria y la necesidad de

137 CANAL, Jordi: El carlismo... p. 140.

138 ARÓSTEGUI, Julio: "La crisis y la Segunda Guerra Carlista (1840-1876)" en ARÓSTEGUI, Julio, CANAL, Jordi y GONZÁLEZ CALLEJA, Eduardo: El carlismo y las guerras carlistas. Hechos, hombres e ideas, Madrid, La esfera de los libros, 2003, p. 74.

139 ADPZ, vigilancia, caja XVI-1189.

140 GARCÍA SANZ, Ángel: "Crisis de la agricultura tradicional y revolución liberal (1800-1850)" en GARCÍA SANZ, Ángel y GARRABOU, Ángel (eds): Historia agraria de la España contemporánea, 
apuntarse a unas fuerzas rebeldes para poder sobrevivir, como había sucedido en la Primera Guerra Carlista. Por todo ello, frente a unos pocos incondicionales de la causa predominaba una gran masa que, aunque hubiera combatido por el carlismo en el pasado, no se sentía atraída por la revuelta armada. De esta manera, la casi totalidad de los pueblos (pese a los temores de los liberales) se mostraron indiferentes, habiendo incluso algunos que se movilizaron contra los rebeldes.

Este escaso apoyo popular podría indicarnos que los pocos que siguieron fieles a la causa carlista lo hacían por motivos personales, más que por causas ideológicas o por intereses de clase. Algunos continuaban en la lucha por su odio hacia el liberalismo, como Manuel Marco, a quien los liberales habían asesinado a un tío canónigo, antes de saquear su casa, casi veinte años antes ${ }^{141}$. Otros, en cambio, buscaban conseguir así un medio de vida, como Pascual Aznar, que se encontraba en la miseria tras habérsele retirado la pensión que recibía por invalidez, por participar en la revuelta de $1848^{142}$. O un ascenso, como probablemente pretendía Cipriano de los Corrales, que había aprendido que los pronunciamientos podían servir para hacer una rápida carrera militar. A todos ellos les seguirían sus amigos, ya fuera por compartir su odio hacia los liberales o porque esperaban obtener algún provecho, si la rebelión triunfaba y su amigo conseguía un puesto importante.

Todo esto llevó al fracaso de la revuelta, ya que sus apoyos venían más de intereses personales de algunos individuos que de un malestar general de la población o de un odio masivo hacia el liberalismo. Este fracaso debió desmoralizar bastante a los carlistas aragoneses, que esperaban contar con la sublevación de más tropas del ejército, así como con el apoyo de los demócratas, algo que no se produjo ${ }^{143}$. Tampoco parece que la llegada al poder del progresismo sirviera para atraer hacia el carlismo a una parte importante del liberalismo más conservador, que no quería recurrir al pueblo para recuperar al poder. En vez de eso, preferían una reacción dirigida por la corona y por el ejército, como efectivamente sucedió poco después. Los partidarios de don Carlos habían pensado hasta entonces que contaban con un amplio apoyo popular en Aragón y que, en cuanto aparecieran allí algunas partidas guerrilleras, se repetirían los hechos de la Primera Guerra Carlista. Al ver que las cosas habían cambiado se volvieron mucho más cautos y no volvieron a intentar nada hasta 17 años más tarde, cuando las circunstancias fueron mucho más favorables.

\section{Bibliografía}

ARÓSTEGUI, Julio: “La crisis y la Segunda Guerra Carlista (1840-1876)” en ARÓSTEGUI, Julio, CANAL, Jordi y GONZÁLEZ CALLEJA, Eduardo, El carlismo y las guerras carlistas. Hechos, hombres e ideas, Madrid, La esfera de los libros, 2003.

Barcelona, Crítica, 1985, v. 1, p. 84.

141 PIRALA, Antonio, Historia contemporánea... v. 2, p. 576.

142 AGMS, primera sección, legajo A-2707.

143 CARPIZO, Esperanza, La Esperanza carlista, Madrid, Editorial Actas, 2008, p. 654. 
CABELLO, Francisco, SANTA CRUZ, Francisco y TEMPRADO, Ramón María: Historia de la guerra última en Aragón y Valencia, Zaragoza, Institución Fernando el Católico y Diputación de Zaragoza, 2006.

CANAL, Jordi: El carlismo. Dos siglos de contrarrevolución en España, Madrid, Alianza editorial, 2000.

CANAL, Jordi: "El carlisme: notes històriques i historiogràfiques" en Lluc: revista de cultura i d'idees, $\mathrm{n}^{\circ}$ 877, 2011.

CALBO Y ROCHINA DE CASTRO, Dámaso: Historia de Cabrera y guerra civil en Aragón, Valencia y Murcia, Madrid, Establecimiento tipográfico de don Vicente Castelló, 1845.

CARIDAD, Antonio: El carlismo en el País Valenciano y Teruel (1833-1840), Valencia, Universidad de Valencia, 2010.

CARPIZO, Esperanza: La Esperanza carlista, Madrid, Editorial Actas, 2008.

CÓRDOBA, Buenaventura: Vida militar y política de Ramón Cabrera, Madrid, Imprenta de Eusebio Aguado, 1844-1846.

CÓRDOBA, Pablo: Historia de don Carlos de Borbón y Este y de su augusta familia desde el convenio de Vergara hasta nuestros días, Madrid, Imprenta de T. Rey, 1870.

DE JAIME, José María y DE JAIME, José: Manuel Marco y Rodrigo. Marco de Bello, Calamocha, Centro de Estudios del Jiloca, 1992.

FERRER, Melchor, TEJERA, Domingo y ACEDO, José: Historia del tradicionalismo español, Sevilla, Ediciones Trajano y Editorial Católica Española, 1941-1960.

GARCÍA SANZ, Ángel: "Crisis de la agricultura tradicional y revolución liberal (1800-1850)" en GARCÍA SANZ, Ángel y GARRABOU, Ramón (eds), Historia agraria de la España contemporánea, Barcelona, Crítica, 1985.

PIRALA, Antonio: Historia de la guerra civil y de los partidos liberal y carlista, Madrid, Turner/ Historia 16, 1984.

PIRALA, Antonio: Historia contemporánea. Segunda parte de la guerra civil. Anales desde 1843 hasta el fallecimiento de don Alfonso XII, Madrid, Felipe González Rojas editor, 1892-1906.

ROLDÁN, E nrique: Estado mayor general carlista en las tres guerras del siglo XIX, Madrid, Editorial Actas, 1998.

RUBIO, Mari Cruz y TALAVERA, María: El carlismo, Madrid, Consejo Nacional de Investigaciones Científicas, 2007.

RÚJULA, Pedro: Rebeldía campesina y guerra civil en Aragón, 1821-1834, Zaragoza, Universidad de Zaragoza, 1994.

RÚJULA, Pedro: Contrarrevolución. Realismo y carlismo en Aragón y el Maestrazgo, 1820-1840, Zaragoza, Prensas Universitarias de Zaragoza, 1998.

SÁNCHEZ i AGUSTÍ, Ferran: "Entrada dels carlins a Balsareny l’any 1855” en Bulletí del Cercle Cultural de Balsareny, n 184, 1991. 